\title{
ANALYSIS PLANNING AND CONTROL OF NON CREDIT DISTRIBUTION IN LOAN PERFORMING PT.BPR-LPN KOTO DALAM
}

\section{PATRIA NAGARA, RINI AFRIANTI, AKMAL HIDAYAT}

Sekolah Tinggi Ilmu Ekonomi Sumatera Barat Pariaman patrianagara@gmail.com, afriantirini9@gmail.com, akmalhidayat@gmail.com

\begin{abstract}
Singer study conducted to determine the effect a review of Planning and Control lending Against soundness ratio of non-performing loans at PT. BPR-LPN Koto Dalam. Purpose Of Research Singer is to review Test Operations And Operating simultaneous partial influence of Planning and Control lending Against soundness ratio of non-performing loans in PT.BPR-LPN Koto Dalam, used multiple linear regression analysis. The research instruments used test is the test of validity and reliability test. The Classical assumption test used is normality test, test multicollinearity, and heteroscedasticity test. As for the review hypothesis test, F test and t test. The analysis tool used to review the planning and Control Testing the effect of lending against soundness ratio of non-performing loans is a regression WITH 17:00 help SPSS version for windows. Research shows that the planning lending On The Level NOT affect the health of non-performing loans. It indicated WITH Singer $t$ Namely-0176 and 0642 sig>0.05 And The significant influences of the loan portfolio BETWEEN Control Against Health Level of non performing loan ratio indicated WITH HAL singer t_hitung That 0012 And 0793 sig <0.05. There is a significant influence BETWEEN The Planning and Control lending Against soundness ratio of non-performing loans is shown WITH HAL singer F_hitung 3,448 and sig $(0.023$ $<0.05)$ and the coefficient of determination $R$ square shows the figure 0327 OR $32.7 \%$. So it can be said that the $32.7 \%$ rate of non-performing loans ratio of health is affected by Planning and Control of credit. While the remaining $67.3 \%$ is influenced by variables studied hearts lie Yang NOT Singer Research.
\end{abstract}

Keywords: planning, control, and non performing loan

Abstrak: Studi Singer dilakukan untuk mengetahui pengaruh tinjauan Perencanaan dan Kontrol pinjaman terhadap rasio kesehatan kredit bermasalah di PT. BPR-LPN Koto Dalam. Tujuan Penelitian ini adalah untuk meninjau Uji Operasi dan Operasi secara simultan pengaruh parsial Perencanaan dan Kontrol pinjaman terhadap rasio kesehatan kredit macet di PT.BPR-LPN Koto Dalam, menggunakan analisis regresi linier berganda. Instrumen penelitian yang digunakan tes adalah tes validitas dan uji reliabilitas. Uji asumsi klasik yang digunakan adalah uji normalitas, uji multikolinieritas, dan uji heteroskedastisitas. Adapun untuk uji hipotesis tinjauan, uji $\mathrm{F}$ dan uji t. Alat analisis yang digunakan untuk meninjau perencanaan dan Kontrol Pengujian efek pinjaman terhadap rasio kesehatan kredit macet adalah regresi SPSS versi 17. Penelitian menunjukkan bahwa perencanaan peminjaman On The Level tidak memengaruhi kesehatan kredit macet. Hal ini ditunjukkan dengan Singer t yaitu -0176 dan 0642 sig> 0,05 Dan Pengaruh signifikan dari portofolio pinjaman antara Kontrol terhadap Tingkat Kesehatan rasio pinjaman bermasalah ditunjukkan dengan hal penyanyian t_hitung Bahwa 0012 Dan 0793 sig <0,05. Ada pengaruh yang signifikan antara Perencanaan dan Pengendalian pinjaman Terhadap rasio kesehatan kredit bermasalah ditunjukkan dengan hal penyanyian $\mathrm{F}$ _hitung 3,448 dan sig $(0,023<0,05)$ dan koefisien determinasi $\mathrm{R}$ square menunjukkan angka 0327 atau 32,7\%. Jadi dapat dikatakan bahwa tingkat $32,7 \%$ rasio kredit macet kesehatan dipengaruhi oleh P-ISSN 2622-9110 Lembaga Penelitian dan Penerbitan Hasil Penelitian Ensiklopedia $\quad 211$ E-ISSN 2654-8399 
Perencanaan dan Pengendalian kredit. Sedangkan sisanya 67,3\% dipengaruhi oleh variabel-variabel yang dipelajari yaitu kesalahan Yang bukan Singer Research.

Kata kunci: perencanaan, kontrol, dan kredit macet

\section{A. Pendahuluan}

Perbankan merupakan salah satu lembaga keuangan yang berperan dalam pembangunan ekonomi, dimana perbankan diharapkan mampu mengembangkan dan memajukan perekonomian. Khususnya dalam meningkatkan pemerataan kesejahteraan masyarakat. Berdasarkan Undang-undang tentang Perbankan No. 10 tahun 1998 bank adalah badan usaha yang menghimpun dana dari maasyarakat dalam bentuk simpanan dan menyalurkan kepada masyarakat dalam bentuk kredit atau bentuk-bentuk lainnya dalam rangka meningkatkan taraf hidup rakyat banyak. Adapun jenis bank menurut Undangundang No. 10 tahun 1998 pasal 5 ayat 1 yaitu: Bank umum adalah Bank yang melaksanakan kegiatan usaha secara konvensional atau berdasarkan prinsip syariah yang dalam kegiatannya memberikan jasa dalam lalu lintas pembayaran. Bank Perkreditan Rakyat adalah Bank yang melaksanakan kegiatan usaha secara konvensional atau berdasarkan prinsip syariah dalam kegiatannya tidak memberikan jasa dalam lalu lintas pembayaran.

Secara garis besar usaha perbankan dapat dibagi dalam tiga kegiatan yaitu: usaha simpanan, usaha pinjaman (kredit) dan usaha jasa bank lainnya. Kegiatan tersebut bertujuan untuk melayani seluruh lapisan masyarakat, baik dari lapisan atas hingga lapisan bawah. Perbankan memberikan kesempatan kepada masyarakat untuk berpartisipasi dalam pembangunan ekonomi dengan mengadakan pengumpulan dana melalui usahausaha yang dijalankan perbankan, seperti tabungan, deposito, dan menyalurkannya dalam bentuk kredit. Dengan adanya tabungan, deposito, dan kredit menimbulkan terjadinya perputaran uang di masyarakat sehingga dapat memperkuat permodalan, agar masyarakat menjadi lebih baik dan sejahtera dari sebelumnya. Kredit menurut Undang-undang No. 10 Tahun 1998 pasal 1ayat 11 merupakan penyediaan uang atau tagihan yang dapat dipersamakan dengan itu berdasarkan persetujuan atau kesepakatan pinjam meminjam antara bank dan pihak lain yang mewajibkan pihak peminjam untuk melunasi hutangnya setelah jangka waktu tertentu dengan pemberian bunga.

Salah satu perbankan yang melakukan penyaluran kredit adalah PT. Bank Perkreditan Rakyat LPN koto dalam. PT.BPR-LPN KOTO DALAM, adalah bank yang berawal dari Lumbung Pitih Nagari, yang didirikan pada tanggal 14 agustus 1975 dengan suran keputusan Gubernur Nomor 114/GSB/1975 tentang penetapan lokasi proyek Lumbung Pitih Nagari, pada tahap kedua tahun 1975 sampai dengan 1976 dengan Surat Keputusan Gubernur tersebut merupakan awal mulai berdirinya LPN Koto Dalam, dan melakukan kegiatannya sejak tanggal 7 juli 1976 sampai pada tanggal 12 januari 1999 ditetapkan bentuk badan hukumnya menjadi Perseroan Terbatas, yang disahkan oleh Menteri Kehakiman Republik Indonesia dengan surat keputusan Nomor : C-1023 HT.01.01.TH.99. Yang diberi nama PT.BANK Perkreditan Rakyat Lumbung Pitih Nagari Koto Dalam, yang beralamat di Pasar Padang Sago Nagari Koto Dalam Kecamatan Padang Sago.

\section{B. Metode Penelitian}

Objek Penelitian. Penelitian ini dilakukan di PT. Bank Perkreditan Rakyat Lumbung Pitih Nagari Koto Dalam yang berlokasi di Pasar Padang Sago Nagari Koto Dalam Kecamatan Padang Sago Kabupaten Padang Pariaman. Jenis Penelitian. 
Penelitian yang dilakukan adalah penelitian penjelasan yang menjelaskan hubungan sebab akibat antara variabel independent dan variabel dependent.

Populasi dan Sampel Menurut Arikunto (2002:108), Populasi adalah keseluruhan subyek penelitian. Populasi dalam penelitian ini adalah seluruh karyawan di PT. BPR LPN KOTO DALAM sebanyak 22 orang. Menurut Sugiyono (1994:57) sampel adalah sebagian dari populasi yang karakteristiknya hendak diselidiki, dan bisa dianggap mewakili keseluruhan populasi jumlahnya sedikit dari pada jumlah populasinya. Menurut Ridwan (2010), apabila populasi kurang dari 30 orang maka populasi dijadikan sampel atau disebut sampel penuh. Dalam penelitian ini peneliti mengambil keseluruhan populasi menjadi sampel yaitu sebanyak 22 orang sampel.

Teknik Analisis Data. Statistik Deskriptif. Analisis ini bermaksud untuk menggambarkan karakteristik masing-masing variabel penelitian. Dengan cara menyajikan data kedalam tabel distribusi frekuensi, menghitung nilai pemusatan (dalam hal ini rata-rata, median dan modus) dan nilai dispersi (standar deviasi dan koefisien variasi) serta menginterprestasikannya. Uji Validitas. Menurut (sekaran:2003) menjelaskan bahwa instrumen penelitian dikatakan valid bila mampu mengukur apa yang seharusnya diukur. Bila instrumen (alat ukur) memiliki tingkat validitas yang tinggi maka semakin kecil varian kesalahan, dan data yang dikumpulkan dapat dipercaya. Uji validitas dilakukan dengan korelasi bivariat yaitu dengan mengkorelasikan item pertanyaan dengan total item pertanyaan (Corrected to total item correlation). Uji Reliabilitas. Reliabilitas menurut Sugiyono (2006:110) merupakan tingkat keandalan suatu instrumen penelitian. Instrumen yang reliabel adalah instrumen yang apabila digunakan berulang kali untuk mengukur objek yang sama akan menghasilkan data yang sama. Uji reliabilitas akan dapat menunjukkan konsistensi dari jawaban-jawaban responden yang terdapat pada kuesioner. Uji ini dilakukan setelah uji validitas dan yang diuji merupakan pertanyaan yang sudah valid. Uji Asumsi Klasik. Suatu model regresi dikatakan linier harus melalui uji asumsi klasik yang terdiri dari uji normalitas, uji linieritas, uji multikolonieritas dan uji heteroskedasitas (Ghozali, 2005).

\section{Hasil dan Pembahasan}

\section{Pengujian Hipotesis}

\section{Analisis Regresi Linear Berganda}

Penilaian ini bertujuan untuk mengetahui dan menganalisis seberapa besar pengaruh perencanaan dan pengendalian kredit terhadap tingkat kesehatan rasio non performing loan. Untuk membahas permasalahan diatas, penulis menggunakan analisa kuantitatif regresi berganda.

Hasil pengujian hipotesis dengan menggunakan analisa regresi berganda diringkas dan disajikan pada tabel 1 berikut ini :

\section{Tabel 1}

\section{Ringkasan Hasil Analisis Regresi Berganda}

Pengaruh Perencanaan Penyaluran Kredit dan Pengendalian Penyaluran Kredit Terhadap Rasio Non Performing Loan

\begin{tabular}{|c|l|r|}
\hline No. & Keterangan & \multicolumn{1}{|c|}{$\begin{array}{c}\text { Nilai Koefisien } \\
\text { Regresi }\end{array}$} \\
\hline 1. & (Constant) & 15,762 \\
\hline 2. & Perencanaan & $-0,176$ \\
\hline 3. & Pengendalian & 0,793 \\
\hline
\end{tabular}

P-ISSN 2622-9110 Lembaga Penelitian dan Penerbitan Hasil Penelitian Ensiklopedia 
Berdasarkan tabel 1 dapat diketahui persamaan regresi yang terbentuk adalah:

$$
\mathrm{Y}=\mathrm{a}+\mathrm{b}_{1} \mathrm{X}_{1}+\mathrm{b}_{2} \mathrm{X}_{2}
$$

$$
Y=15,762+(0,176) X_{1}+0,793 X_{2}
$$

Keterangan :

$\mathrm{Y}=$ Rasio Non Performing Loan

$\mathrm{X} 1=$ Perencanaan Penyaluran Kredit

X2= Pengendalian Penyaluran Kredit

Dari persamaan tersebut dapat dijelaskan bahwa: 1) Variabel Perencanaan Penyaluran Kredit dan Pengendalian Penyaluran Kredit mempunyai arah koefisien yang bertanda positif terhadap tingkat kesehatan Rasio Non Performing Loan; 2) Koefisien Perencanaan Penyaluran Kredit memberikan nilai koefisien sebesar -0,176 yang berarti bahwa jika Perencanaan Penyaluran Kredit meningkat sebesar satu satuan dengan asumsi variabel lain (Pengendalian Penyaluran Kredit) tetap maka tingkat kesehatan Rasio Non Performing Loan akan mengalami penurunan sebesar 0,176 (17,6\%); dan 3) Koefisien Pengendalian Penyaluran Kredit memberikan nilai koefisien sebesar 0,793 yang berarti bahwa jika Pengendalian Penyaluran Kredit meningkat sebesar satu satuan dengan asumsi variabel lain (Perencanaan Penyaluran Kredit) maka tingkat kesehatan Rasio Non Performing Loan akan mengalami peningkkatan sebesar $0,793(79,3 \%)$.

Koefisien Korelasi dan Koefisien Determinasi. Hasil uji koefisien korelasilinier berganda untuk perencanaan dan pengendalian penyaluran kredit terhadap tingkat kesehatan Rasio non performing loan adalah seperti yang dikemukakan pada tabel 2

\section{Tabel 2}

Hasil Uji Koefisien Korelasi Linier Berganda

\begin{tabular}{|c|c|}
\hline Keterangan & Nilai \\
\hline $\begin{array}{c}\text { Koefisien Korelasi } \\
\text { Linier Berganda }\end{array}$ & 0,572 \\
\hline
\end{tabular}

Sumber: Hasil pengolahan data, 2016

Hasil dari analisa koefien korelasilinier berganda seperti yang dikemukakan pada Table 2 diperoleh hubungan variable bebas dengan variabel terikat dengan nilai koefisien korelasilinier berganda adalah 0,572 berarti nilai korelasi berada diantara 0,41 sampai dengan 0,70 maksudnya perencanaan dan pengendalian penyaluran kredit memiliki keeratan kuat terhadap tingkat kesehatan rasio non performing loan. Selanjutnya, uji Koefisien Determinasi digunakan untuk melihat kelayakan penelitian yang dilakukan dengan melihat pengaruh variabel independent terhadap variabel dependent yang dapat diperlihatkan pada Tabel 3 berikut :

\section{Tabel 3}

\section{Hasil Pengujian Uji Determinasi ( $R$ Square)}

\begin{tabular}{|l|l|}
\hline \multicolumn{1}{|c|}{ Keterangan } & Nilai \\
\hline $\begin{array}{l}\text { Koefisien Determinasi } \\
\text { Linier Berganda }\end{array}$ & 0,327 \\
\hline
\end{tabular}

Sumber : data primer diolah, 2016 
Berdasarkan Tabel 3 diatas dapat dilihat besar nilai $R$ Square sebesar 0,327 hal ini berarti $32,7 \%$ dari variasi variabel tingkat kesehatan rasio non performing loan dipengaruhi oleh perencanaan dan pengendalian penyaluran kredit.

\section{Uji t ( Uji Hipotesis Secara Parsial)}

Hipotesis dalam penelitian ini diuji kebenarannya dengan menggunakan uji parsial. Pengujian dilakukan dengan melihat taraf signifikansi (p-value), jika taraf signifikansi yang dihasilkan dari perhitungan di bawah 0,05 maka hipotesis diterima, sebaliknya jika taraf signifikansi hasil hitung lebih besar dari 0,05 maka hipotesis ditolak.

Tabel 4

Hasil Uji t Secara Parsial

\begin{tabular}{|l|r|r|}
\hline \multicolumn{1}{|c|}{ Variabel Bebas } & t-hit & \multicolumn{1}{c|}{ Sign. T } \\
\hline Perencanaan $\left(\mathrm{X}_{1}\right)$ & $-0,472$ & 0,642 \\
\hline Pengendalian $\left(\mathrm{X}_{2}\right)$ & 2,771 & 0,012 \\
\hline
\end{tabular}

Sumber : data primer diolah, 2016

\section{Uji Hipotesis $1\left(\mathbf{H}_{1}\right)$}

Perumusan Hipotesis :

Ho $: b \neq 0$ berarti ada pengaruh yang signifikan antara perencanaan penyaluran kredit dengan tingkat kesehatan rasio non performing loan.

$\mathrm{Ha}: \mathrm{b}=0$ berarti tidak ada pengaruh yang signifikan antara perencanaan penyaluran kredit dengan tingkat kesehatan rasio non performing loan.

\section{Uji Hipotesis $2\left(\mathbf{H}_{2}\right)$}

Perumusan Hipotesis :

Ho $: b \neq 0$ berarti ada pengaruh yang signifikan antara pengendalian penyaluran kredit dengan tingkat kesehatan rasio non performing loan.

$\mathrm{Ha}: \mathrm{b}=0$ berarti tidak ada pengaruh yang signifikan antara pengendalian penyaluran kredit dengan tingkat kesehatan rasio non performing loan.

\section{Uji F (Uji Hipotesis Secara Simultan)}

Untuk menguji pengaruh variabel bebas secara bersama-sama diuji dengan menggunakan uji F. Berdasarkan Tabel 5 dapat disimpulkan bahwa pengujian pengaruh variabel bebas secara bersama-sama terhadap variabel terikatnya dilakukan dengan menggunakan uji $\mathrm{F}$. Hasil perhitungan statistik menunjukkan nilai $\mathrm{F}$ hitung $=$ 4,614. Dengan menggunakan batas signifikansi 0,023, maka diperoleh nilai signifikansi tersebut lebih kecil dari 0,05. Hal ini berarti bahwa hipotesis yang menyatakan bahwa secara simultan variabel perencanaan dan pengendalian penyaluran kredit mempunyai pengaruh terhadap tingkat kesehatan rasio non performing loan.

Hasil perhitungan regresi secara simultan diperoleh sebagai berikut :

Tabel 5

Hasil Uji F

\begin{tabular}{|l|c|c|c|}
\hline \multicolumn{1}{|c|}{ Variabel } & F-hit & $\begin{array}{c}\text { Nilai } \\
\text { Signifikasi }\end{array}$ & $\begin{array}{c}\text { Level of } \\
\text { Significant }\end{array}$ \\
\hline $\begin{array}{l}\text { Perencanaan dan } \\
\text { Pengendalian penyaluran }\end{array}$ & 4,614 & 0,023 & 0,05 \\
\hline
\end{tabular}

Sumber : data primer diolah, 2016 (Lampiran 6 ) 
Dari hasil pengolahan data diatas dapat diperoleh interprestasi dari penelitian ini adalah sebagai berikut: 1) Berdarkan hasil pengujian hipotesis pertama diperoleh bahwa perencanaan penyaluran kredit tidak berpengaruh signifikan terhadap tingkat kesehatan rasio non performing loan pada PT BPR-LPN Koto Dalam. Pembuktian bahwa variabel ini mempunyai pengaruh yang tidak signifikan ditunjukkan dengan derajat signifikansi yang berada di atas 0,05 yaitu sebesar 0,642 dan rata-rata TCR adalah 51, Hasil penelitian ini tidak sesuai Rini Gustifa (2010) factor-faktor yang mempengaruhi kredit macet pada koperasi simpan pinjam di kota padang. Hasil penelitian Rini Gustifa menunjukan bahwa fariabel tingkat suku bunga, jangka waktu,stabilitas penjualan dan komitmen anggota koperasi secara bersma-sama berpengaruh terhadap kredit macet ; 2) Berdasarkan hasil pengujian hipotesis kedua diperoleh bahwa pengendalian penyaluran kredit berpengaruh signifikan terhadap tingkat kesehatan rasio non performing loan pada PT.BPR-LPN Koto Dalam. Pembuktian bahwa variabel ini mempunyai pengaruh yang signifikan ditunjukkan dengan derajat signifikansi yang berada diatas 0,05 yaitu sebesar 0,012 . dan rata-rata TCR adalah 77. Hasil penelitian ini sesuai dengan penelitian yang dilakukan oleh Dewantri Wahyuni Mointi (2014) "Pengaruh pengendalian intern prosedur pemberian kredit terhadap pengembalian piutang pada PT.Bank Sumut cabang Limboto; dan 3) Dari hasil uji F didapatkan hasil nilai signifikansi F lebih kecil dari level of significant ( $\alpha$ ) 0,05. Hal ini menunjukkan adanya pengaruh signifikan secara bersamaan antara perencanaan dan pengendalian penyaluran kredit terhadap tingkat kesehatan non performing loan. Besarnya pengaruh perencanaan dan pengendalian penyaluran kredit terhadap tingkat kesehatan non performing loan adalah $32,7 \%$ sedangkan sisanya sisanya $67,3 \%$ dipengaruhi oleh selain model yang diteliti, seperti komitmen, pelayanan, kedekatan emosional dan lain-lain.

\section{Penutup}

Berdasarkan uraian dan hasil analisis pada bab-bab sebelumnya dan merujuk pada topic pembahasan mengenai pengaruh perencanaan dan pengendalian penyaluran kredit terhadap tingkat kesehatan rasio non performing loan pada PT. BPR-LPN Koto Dalam, dapat dikemukakan kesimpulannya sebagai berikut: 1) Perencanaan tidak berpengaruh terhadap tingkar kesehatan rasio non performing loan karena nilai koefisien regresi perencanaaan sebesar $-0,472$ dan nilai sig 0,642 lebih besar dari pada level of significant $(\alpha) 0,05 ; 2)$ Pengendalian berpengaruh signifikan positif terhadap tingkat kesehatan rasio non performing loan karena nilai koefisien regresi pengendalian bernilai positif yaitu 2,771 dan nilai sig 0,012 lebih kecil dari pada level of significant (a) 0,05 ; dan 3) Perencanaan dan pengendalian berpengaruh signifikan terhadap tingkat kesehatan non performing loan karena nilai sig 0,023 lebih kecil dari pada level of significant ( $\alpha$ ) 0,05 dan 32,7\% dipengaruhi oleh perencanaan dan pengendalian kredit sedangkan $67,3 \%$ dipengaruhi oleh selain model yang diteliti, seperti komitmen, pelayanan, kedekatan emosional dan lain-lain.

\section{Daftar Pustaka}

Abdurrahman, A, Ensiklopedia Ekonomi Keuangan Perdagangan, Pradnya Paramita, Jakarta, 1993.

Agus Rahmat 2012. Analisis Penyelamtan kredit macet

Arikunto, Suharsimi. 1998. Prosedur Penelitian Suatu Pendekatan Praktek. Yogyakarta, Rineka Cipta 
Dendawijaya, Lukman, 2005. Manajemen Perbankan, Edisi Kedua, Cetakan Kedua, Ghalia Indonesia, Bogor Jakarta

Ghozali, I., \& Fuad. 2005. Structural Equation Modelling. Semarang: Badan Penerbit Universitas Diponegoro.

Ghozali, Imam, 2006. Aplikasi Analisis Multivariate dengan Program SPSS, Semarang : Badan Penerbit Universitas Diponegoro.

Ghozali, Imam 2007, Aplikasi Analisis Multivariate dengan program SPSS. PT.Gramedia Pustaka Utama. Jakarta.

Ghozali, Imam. 2008. Konsep dan Aplikasidengan Program Amos 16.0. Semarang: Badan Penerbit Universitas Diponegoro

Hasibuan, Melayu S.P, 2002. Manajemen Sumber Daya Manusia, Bumi Aksara, Jakarta

Kasmir. 2003. Bank Dan Lembaga Keuangan lainnya. Jakarta: PT Raja GrafindoPersada

Kasmir. 2010. Dasar-dasar Perbankan, Edisi 1-8. Jakarta: Rajawali Pers

Kuncoro dan Suhardjono, 2002, Manajemen Perbankan (Teori dan Aplikasi), Edisi Pertama, Penerbit BPFE, Yogyakarta.

Laurensius Arliman S, Perlindungan Hukum Terhadap Anak Yang Tereksploitasi Secara Ekonomi Di Kota Padang, Jurnal Arena Hukum, Volume 9, Nomor 1, 2016.

Laurensius Arliman S, Lembaga-Lembaga Negara Independen (Di Dalam Undang-Undang Dasar Negara Republik Indonesia Tahun 1945), Deepublish, Yogyakarta, 2016.

Laurensius Arliman S, Keterbukaan Keuangan Partai Politik terhadap Praktik Pencucian Uang dari Hasil Tindak Pidana Korupsi, Jurnal Cita Hukum,Volume 4, Nomor 2, 2016.

Mamduh. M. Hanafi. (2003). Analisis Laporan keuangan, Penerbit UPP AMK YKPN, Yogyakarta.

Nurul dan Raina Linda Sari 2011. Analisis Kebijakan Pemberian kredit dan Pengaruh Terhadap NPL dan LDR

Rivai, Veithzal, 2006. Manajemen Sumber Daya Manusia untuk Perusahaan: dari Teori Ke Praktik, Edisi Pertama, Penerbit PT. Raja Grafindo Persada, Jakarta.

Rivai, Veithzal 2004. Kepemimpinan dan Perilaku Organisasi, Edisi Kedua, Cetakan Kedua, Penerbit PT. Raja Grafindo Persada, Jakarta.

Sekaran, 2003. Research Method For Business, Jakarta : Salemba Empat

Septa Priaga Putra 2015. Analisis Menajemen Resiko Kredit Sebagai Meminimalisir Resiko Kredit

Septian Fika Widiya Ningrum 2010. Analisis Pengelolaan Kredit dan Upaya Meningkatkan Likuiditas

Sugiyono. 2006. Metode Penelitian Kuantitatif Kualitatif dan R \& D. Alfabeta. Bandung Singarimbun, Masri, dkk. 1995. Metode Penelitian Survei. LP3ES. Jakarta

Sinungan, Muchdarsyah. 2002. Produktifitas Apa dan Bagaimana. Jakarta: Bumi Aksara. Suyatno, Thomas, Kelembagaan Perbankan, Jakarta: Gramedia Pustaka Utama, 2003

Weni Izriana 2012. Analisis Penyaluran Kredit BPR Terhadap Pendapatan Pengusaha Kecil 